\title{
NUTRIÇÃO E PRODUTIVIDADE DE GRÃOS DA AVEIA-PRETA EM FUNÇÃO DA APLICAÇÃO DE CALCÁRIO E GESSO EM SUPERFÍCIE NA IMPLANTAÇÃO DO SISTEMA PLANTIO DIRETO(1)
}

\author{
Rogério Peres Soratto ${ }^{(2)} \&$ Carlos Alexandre Costa Crusciol ${ }^{(3)}$
}

\begin{abstract}
RESUMO
A nutrição e produtividade das culturas podem ser afetadas pelas modificações químicas do solo causadas pela calagem e aplicação de gesso em superfície. Este trabalho objetivou avaliar o efeito da aplicação de calcário e gesso em superfície, na implantação do sistema plantio direto, sobre a nutrição e a produtividade de grãos da aveia-preta, em região de inverno seco, em área anteriormente utilizada com preparo convencional. O experimento foi realizado durante 2003 e 2004, em um Latossolo Vermelho distroférrico, em Botucatu (SP). O delineamento foi de blocos casualizados com parcelas subdivididas e quatro repetições. As parcelas $(18,0 \times 5,4 \mathrm{~m})$ foram constituídas por quatro doses de calcário dolomítico $(0,1.100$, 2.700 e $\left.4.300 \mathrm{~kg} \mathrm{ha}^{-1}\right)$, com PRNT $=71,2 \%$, e as subparcelas $(9,0 \times 5,4 \mathrm{~m})$ pela aplicação ou não de $2.100 \mathrm{~kg} \mathrm{ha}^{-1}$ de gesso agrícola. O aumento no teor de Ca no solo, provocado pela aplicação de calcário e gesso, diminuiu o teor de Mg na folha bandeira da aveia-preta em ano com deficiência hídrica. A aplicação de calcário em superfície aumentou os teores de $\mathrm{K}$ e reduziu os de $\mathrm{Cu}$ e $\mathrm{Fe}$, e a aplicação de gesso agrícola aumentou o teor de $\mathrm{S}$ na folha bandeira da aveia-preta. A calagem em superfície aumentou a produtividade de grãos da aveia-preta, em ano com deficiência hídrica, com efeitos mais pronunciados na presença de aplicação de gesso.
\end{abstract}

Termos de indexação: Avena strigosa, acidez do solo, teor de nutrientes, calagem, componentes da produção.

\footnotetext{
(1) Parte da Tese de Doutorado do primeiro autor apresentada à Faculdade de Ciências Agronômicas, Universidade Estadual Paulista - FCA/UNESP. Recebido para publicação em março de 2007 e aprovado em outubro de 2007.

(2) Professor Assistente Doutor do Departamento de Produção Vegetal, Faculdade de Ciências Agronômicas, Universidade Estadual Paulista - FCA/UNESP. Campus de Botucatu, Caixa Postal 237, CEP 18603-970 Botucatu (SP). E-mail: soratto@fca.unesp.br

(3) Professor Adjunto do Departamento de Produção Vegetal, FCA/UNESP. Bolsista do CNPq. E-mail: crusciol@fca.unesp.br
} 


\title{
SUMMARY: NUTRITION AND GRAIN YIELD OF BLACK OAT AS AFFECTED BYSURFACE APPLICATION OF LIME AND PHOSPHOGYPSUM AT THE ESTABLISHMENT OF NO-TILLAGE SYSTEM
}

\begin{abstract}
Nutrition and crop yield can be affected by chemical modifications of the soil owing to lime and phosphogypsum surface application. The purpose of this study was to evaluate the effects of surface application of lime and phosphogypsum, at the establishment of a notillage system, on nutrition and grain yield of black oat, in a dry-winter region, in area previously used with conventional tillage. The experiment was carried out in 2003 and 2004, on a Haplorthox in Botucatu County, São Paulo State, Brazil. A randomized complete block design was used in a split-plot scheme with four replications. The plots $(18.0 \times 5.4 \mathrm{~m})$ were composed by four dolomitic limestone levels (0; 1,100; 2,700; and 4,300 kg ha-1), with Neutralization Power $=84.3 \%$ and Reactivity $=84.5 \%$, and the subplots $(9.0 \times 5.4 \mathrm{~m})$ were composed by without and with phosphogypsum application $\left(2,100 \mathrm{~kg} \mathrm{ha}^{-1}\right)$. The increase in soil Ca as a result of lime and phosphogypsum application, reduced the Mg content in the black oat flag leaf in a year with water deficiency. Surface liming increased K and reduced $\mathrm{Cu}$ and $\mathrm{Fe}$ concentration in the black oat flag leaf. Surface application of phosphogypsum increased the $S$ content in the black oat flag leaf. Surface liming increased the black oat grain yield in the year with water deficiency, with higher effects being observed when phosphogypsum was applied.
\end{abstract}

Index terms: Avena strigosa, liming, nutrient content, soil acidity, yield components.

\section{INTRODUÇÃO}

Períodos de entressafra, terras ociosas e solos desprotegidos no período de outono-inverno são situações que não condizem com o potencial produtivo do Brasil (Baier et al., 1988) e não devem ocorrer em sistemas agrícolas sustentáveis (Seixas et al., 2004). A distribuição irregular e a baixa precipitação pluvial são os principais fatores que afetam a produtividade das culturas anuais no cultivo de outono-inverno no Brasil. Nesse sentido, são importantes estudos de técnicas e culturas que possibilitem o cultivo nesse período de deficiência hídrica, gerando alternativas e incremento de renda ao produtor.

A adoção do sistema plantio direto, com rotação de culturas, promove inúmeros benefícios ao solo, como maior proteção contra o impacto direto das gotas de chuva, favorecimento da infiltração, redução da perda de água por escoamento superficial, e redução da perda de solo e nutrientes por erosão (Hermani et al., 1999; Stone \& Silveira, 1999; Caires et al., 2005). Esses fatores propiciam maior disponibilidade de água e nutrientes às plantas, melhora as condições químicas e físicas do solo, com o aumento da matéria orgânica (Balbino et al., 1996). Isso tem aumentado o interesse do estabelecimento de culturas pelo sistema plantio direto, em áreas anteriormente cultivadas no sistema convencional de preparo do solo, ou sob pastagens, uma vez que elimina o revolvimento do solo para a incorporação de corretivos.

A calagem é prática comumente utilizada para neutralizar a acidez, restaurar a capacidade produtiva dos solos, aumentando a disponibilidade de nutrientes e diminuindo os elementos tóxicos (Pavan \& Oliveira,
2000; Caires et al., 2001). O calcário, quando misturado ao solo e na presença de água, dissolve-se e o carbonato de cálcio dissocia-se (Bohnen, 2000; Quaggio, 2000). Os produtos da dissolução do calcário reagem com os colóides do solo e, nessa reação, elevam o pH, os teores de Ca e a saturação por bases, e diminui Al e Mn trocáveis no solo (Caires et al., 2001).

Todavia, considerando que a calagem em superfície pode ter ação limitada às camadas superficiais, principalmente nos primeiros anos de cultivo, a aplicação de gesso agrícola em superfície é apontada como uma alternativa para a melhoria do ambiente radicular, compensando o reduzido efeito do calcário no subsolo, nos primeiros anos de cultivo, sem necessidade de incorporação prévia do calcário (Caires et al., 2003). O interesse pelo uso de gesso agrícola para diminuir o problema da acidez do subsolo é decorrente da sua maior solubilidade. O gesso agrícola aplicado na superfície do solo movimenta-se ao longo do perfil sob a influência da percolação de água (Caires et al., 1999). Como conseqüência, obtêm-se aumento no suprimento de cálcio e redução da toxidez de alumínio no subsolo (Caires et al., 1999, 2003).

Vários resultados indicaram aumento de produtividade de soja, milho e trigo em função da aplicação superficial de calcário, em sistema plantio direto já estabelecido (Oliveira \& Pavan, 1996, Sá, 1999; Caires et al., 2002b, 2004) e de soja e milho na implantação do sistema plantio direto (Barizon, 2001; Mello, 2001; Lima, 2004). Segundo Caires et al. (2001), a calagem em superfície não interferiu na nutrição e produtividade da cevada, e a aplicação de gesso melhorou a absorção de N, P, K, Ca e S, em condições de deficiência de água, proporcionando acréscimos na 
produção de grãos, em decorrência de aumento do Ca trocável, da relação $\mathrm{Ca} / \mathrm{Mg}$ e do $\mathrm{S}_{-} \mathrm{SO}_{4}{ }_{4}^{2-}$ disponível no solo. A aplicação de gesso em superfície na implantação do sistema plantio direto foi eficiente na melhoria do ambiente radicular e interferiu na nutrição da cultura da soja, porém, não afetou a produtividade da cultura, provavelmente devido à ausência de déficit hídrico (Caires et al., 2003). Já Caires et al. (2004) observaram aumento na produtividade de milho em função da aplicação de gesso em superfície com calagem, mesmo com boa disponibilidade hídrica.

A aveia-preta (Avena strigosa Schreber) é utilizada para adubação verde e como planta de cobertura do solo na entressafra em sistema plantio direto, podendo ainda ser empregada para pastejo direto, fenação e ensilagem (Salermo \& Vetterle, 1984; Rosseto \& Nakagawa, 1995), ou para aproveitamento de grãos na formulação de concentrados para animais (Derpsch \& Calegari, 1992; Nakagawa \& Rosolem, 2005). É considerada rústica e tolerante à seca, em razão do sistema radicular bastante desenvolvido, mais resistente à pragas e doenças, em comparação à aveia branca, e com elevada produção de massa de matéria seca, mesmo em solos pobres em fertilidade (Derpsch \& Calegari, 1992; Calegari, 2001). No entanto, apesar das importantes características de interesse agronômico apresentadas pela aveia-preta, são praticamente inexistentes na literatura dados referentes ao efeito da aplicação de calcário e gesso em superfície sobre a nutrição e a produtividade de grãos dessa cultura, em região de inverno seco.

O trabalho parte da seguinte hipótese: apesar da aveia-preta ser considerada uma planta tolerante à seca e à baixa fertilidade do solo (Derpsch \& Calegari, 1992; Calegari, 2001), o que mais limita a sua produtividade em região de inverno seco são os baixos valores de $\mathrm{pH}$ e teores reduzidos de bases no solo. Assim, a aplicação de corretivos em superfície pode melhorar a disponibilidade de nutrientes no solo, interferindo na nutrição, no desenvolvimento e na produtividade dessa cultura.

Este trabalho objetivou avaliar o efeito da aplicação de calcário e gesso em superfície sobre a nutrição e a produtividade de grãos da aveia-preta, em região de inverno seco, em área anteriormente utilizada com preparo convencional.

\section{MATERIAL E MÉTODOS}

O trabalho foi realizado na Fazenda Experimental Lageado, pertencente à Faculdade de Ciências Agronômicas - Unesp, município de Botucatu, SP, a $48^{\circ} 23^{\prime} \mathrm{W}$ e $22^{\circ} 51^{\prime} \mathrm{S}, 765 \mathrm{~m}$ de altitude. O clima, conforme a classificação de Köppen, é do tipo Cwa, que se caracteriza como tropical de altitude, com inverno seco e verão quente e chuvoso. Os dados referentes às precipitações pluviais no período do experimento estão apresentados na figura 1.

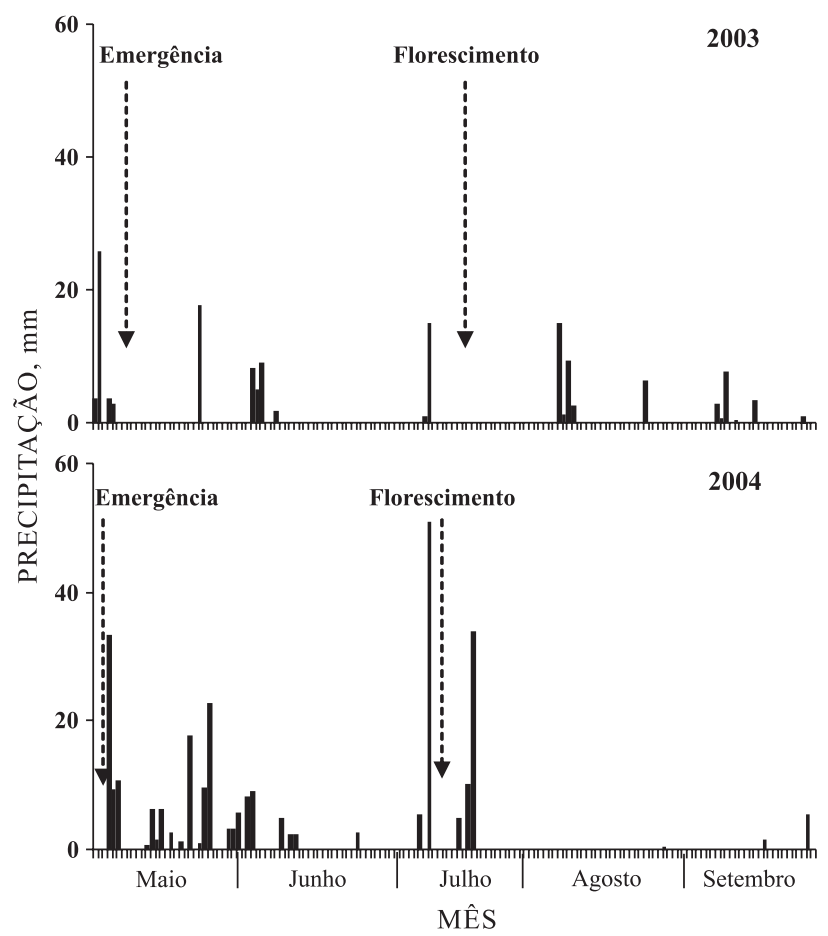

Figura 1. Valores diários de precipitação pluvial ( $\mathrm{mm} \mathrm{dia}^{-1}$ ) obtidos na área experimental, durante o período de maio a setembro, nos anos de 2003 e 2004, e datas de emergência e florescimento pleno da cultura da aveia-preta. Botucatu, SP.

O solo do local é um Latossolo Vermelho distroférrico, o qual permaneceu dois anos em pousio. Em fevereiro de 2001 , foi cultivada soja (safrinha) mediante preparo de solo convencional (uma aração e duas gradagens). Em outubro de 2001, a área experimental foi subsolada, e semeou-se guandu (Cajanus cajan (L.) Millsp.), que foi manejado com triturador de palha em 02/10/2002. Em agosto de 2002, foram coletadas amostras na profundidade de $0-0,20 \mathrm{~m}$ para a determinação das características químicas (Raij et al., 2001) e granulométricas (Embrapa, 1997), cujos resultados foram: matéria orgânica, $20,9 \mathrm{~g} \mathrm{dm}^{-3} ; \mathrm{pH}$ $\left(0,01 \mathrm{~mol} \mathrm{~L}^{-1} \mathrm{CaCl}_{2}\right), 4,2 ; \mathrm{P}$ (resina), $9,2 \mathrm{mg} \mathrm{dm}^{-3} ; \mathrm{K}$, Ca, $\mathrm{Mg}$ e CTC, 1,2, 14,0, 5,0 e 58,0 $\mathrm{mmol}_{\mathrm{c}} \mathrm{dm}^{-3}$, respectivamente, e saturação por bases, $37 \%$ e teores de areia, silte e argila, respectivamente de 545, 108 e $347 \mathrm{~g} \mathrm{~kg}^{-1}$. O solo também apresentava $360 \mathrm{~g} \mathrm{~kg}^{-1} \mathrm{de}$ argila na camada de $0,20-0,40 \mathrm{~m}$ de profundidade.

O delineamento experimental utilizado foi em blocos casualizados, em esquema de parcelas subdivididas, com quatro repetições. Os tratamentos foram constituídos por quatro doses de calcário dolomítico $\left(0,1.100,2.700\right.$ e $\left.4.300 \mathrm{~kg} \mathrm{ha}^{-1}\right)$, que apresentava $23,3 \%$ de $\mathrm{CaO}, 17,5 \%$ de $\mathrm{MgO}$ e $71,2 \%$ de PRNT, visando elevar a saturação por bases para 50,70 e $90 \%$, respectivamente, combinadas com a aplicação ou não de $2.100 \mathrm{~kg} \mathrm{ha}^{-1}$ de gesso agrícola (20 \% de Ca e 16 \% de S). Nas parcelas, com dimensão 
de $18,0 \times 5,4 \mathrm{~m}\left(97,2 \mathrm{~m}^{2}\right)$, foram aplicadas as doses de calcário e as subparcelas, com dimensão de $9,0 \times 5,4 \mathrm{~m}\left(48,6 \mathrm{~m}^{2}\right)$, foram formadas pelos tratamentos de gesso. Foram mantidas distâncias de $8,0 \mathrm{~m}$ entre as parcelas dentro de cada bloco e de 3,0 m entre os blocos. Para as avaliações, foram descartadas as bordaduras de $0,5 \mathrm{~m}$ nas extremidades de cada unidade experimental.

A calagem foi realizada sobre os restos culturais de guandu no dia 15/10/2002, nas parcelas onde estava previsto este tratamento. No dia 16/10/2002, realizouse a aplicação de gesso agrícola em metade de todas as parcelas. Tanto o calcário quanto o gesso foram aplicados superficialmente, sem incorporação ao solo.

Nas safras de verão dos anos agrícolas de 2002/03 e 2003/04, foram cultivadas na área, respectivamente, as culturas de arroz de terras altas e de feijão. A adubação básica, em ambos os cultivos, constituiu-se de $300 \mathrm{~kg} \mathrm{ha}^{-1}$ da fórmula-NPK 08-28-16 + 4,5\% de $\mathrm{S}+0,5 \%$ de Zn.

Após a colheita das culturas de verão, nos dois anos agrícolas, foi semeada aveia-preta cv Comum, em 30/ 4/2003 e 26/4/2004, em toda a área experimental, num espaçamento entre linhas de $0,17 \mathrm{~m}$ e cerca de 70 sementes por metro. Cada subparcela foi constituída por 26 linhas de $9 \mathrm{~m}$ de comprimento. A adubação básica constituiu-se de $200 \mathrm{~kg} \mathrm{ha}^{-1}$ da fórmula-NPK 10-20-10 + 4,5 \% de S no primeiro ano, e $200 \mathrm{~kg} \mathrm{ha}^{-1}$ de $04-20-10+7,0 \%$ de $\mathrm{S}$ no segundo ano. A emergência das plantas ocorreu em 8/5/2003 e 2/5/ 2004.

Foram realizadas amostragens de solo nas camadas de $0-0,05,0,05-0,10$ e $0,10-0,20 \mathrm{~m}$ de profundidade, antes da semeadura da aveia-preta nos dois cultivos, ou seja, aos seis e 18 meses após a aplicação dos corretivos. Foram retiradas sete amostras simples na área útil de cada subparcela, para constituir uma amostra composta, sempre na entrelinha da cultura, com a utilização de trado tipo sonda. As amostras compostas foram secas ao ar e peneiradas (malha $2 \mathrm{~mm}$ ). Posteriormente, foram submetidas à análise para determinação do $\mathrm{pH}\left(0,01 \mathrm{~mol} \mathrm{~L}^{-1} \mathrm{CaCl}_{2}\right), \mathrm{Ca}^{2+}$, $\mathrm{Mg}^{2+} \mathrm{e} \mathrm{K}^{+}$, conforme metodologia proposta por Raij et al. (2001). O S-SO ${ }_{4}^{2-}$ foi determinado segundo Vitti (1988). Os resultados estão apresentados no quadro 1.

No florescimento da cultura, ou seja, em 19/7/2003 e 16/7/2004, foram coletados, ao acaso, 50 folhas bandeiras (limbo) em cada subparcela, indicadas como folha de diagnose, segundo Cantarella et al. (1996). O material foi seco em estufa a $65^{\circ} \mathrm{C}$ até peso constante. Em seguida, as folhas foram moídas e submetidas à análise química para determinação dos teores dos nutrientes (N, P, K, Ca, Mg, S, Cu, Fe, Mn e Zn), segundo os métodos descritos por Malavolta et al. (1997).

Por ocasião da colheita, que ocorreu em 22/08/2003 e 31/08/2004, foram determinadas as seguintes variáveis: (a) altura de planta (distância média compreendida entre o nível do solo e a extremidade superior da panícula mais alta no estágio de grãos em estado duro, em 10 plantas ao acaso, na área útil de cada subparcela); (b) número de panículas por metro quadrado (contagem do número de panículas contidas em 2,0 m de fileira de cada unidade experimental e calculado por metro quadrado, no momento da colheita); (c) número total de espiguetas por panícula (contagem do número de espiguetas de 15 panículas por unidade experimental, coletadas na área útil de cada subparcela); (d) fertilidade das espiguetas (determinada a partir da relação: número de espiguetas granadas por panícula pelo número total de espiguetas por panícula, multiplicada por cem); (e) massa de 1.000 grãos (determinado através da coleta ao acaso e pesagem de quatro amostras de 1.000 grãos de cada subparcela e ajustado para $130 \mathrm{~g} \mathrm{~kg}^{-1}$ de umidade); e (f) produtividade de grãos (determinada mediante a colheita manual de três fileiras de plantas de $7 \mathrm{~m}$ de comprimento em cada subparcela. Após a colheita, foram feitas trilha manual, secagem à sombra e limpeza do material, separando-se a palha e os grãos chochos com auxílio de uma peneira, mediante abanação manual. Em seguida, foi determinado o peso dos grãos colhidos para o cálculo da produtividade de grãos $\left(\mathrm{kg} \mathrm{ha}^{-1}\right)$, e ajustada para $130 \mathrm{~g} \mathrm{~kg}^{-1} \mathrm{de}$ umidade.

Os dados foram submetidos à análise de variância. $\mathrm{Na}$ ausência de interação significativa entre os fatores, as médias referentes à aplicação de gesso foram comparadas pelo teste t a $5 \%$ de probabilidade e os efeitos das doses de calcário por meio de análise de regressão. Com interação significativa, realizou-se o seu desdobramento, utilizando-se o teste t, a $5 \%$, para comparar os efeitos da aplicação de gesso dentro de cada dose de calcário, e análise de regressão para verificar o efeito da calagem dentro de cada tratamento de gesso. Adotou-se como critério para escolha do modelo a magnitude dos coeficientes de regressão significativos a $5 \%$ pelo teste $\mathrm{F}$.

\section{RESULTADOS E DISCUSSÃO}

Os teores de $\mathrm{N}$ na folha bandeira da aveia-preta não foram afetados pela aplicação de gesso ou pela calagem em superfície em nenhum dos anos de cultivo (Quadro 2). Vale destacar que, em todos os tratamentos, os teores desse nutriente encontravamse acima da faixa considerada adequada para aveia (Cantarella et al., 1996) e dos valores observados por Nakagawa \& Rosolem (2005) para a aveia-preta, indicando que tal nutriente não limitou o desenvolvimento da cultura.

$\mathrm{O}$ teor de $\mathrm{P}$ na folha bandeira foi afetado apenas pela calagem no segundo ano de cultivo (Quadro 2). Caires \& Fonseca (2000) observaram aumento da absorção de P pela soja em função da aplicação doses de calcário em superfície. De acordo com esses autores, o aumento da disponibilidade de $\mathrm{P}$ no solo se 
Quadro 1. Resultado da análise química de amostras de solo coletadas nas camadas de 0-0,05, 0,05-0,10 e 0,10-0,20 m de profundidade, aos seis e 18 meses após a aplicação de calcário e gesso em superfície de Latossolo Vermelho distroférrico

\begin{tabular}{|c|c|c|c|c|c|c|c|c|c|c|c|}
\hline \multirow[b]{2}{*}{ Profundidade } & \multirow[b]{2}{*}{ Tratamento } & \multicolumn{2}{|c|}{$\mathrm{pH}\left(\mathrm{CaCl}_{2}\right)$} & \multicolumn{2}{|c|}{$\mathrm{Ca}^{2+}$} & \multicolumn{2}{|c|}{$\mathrm{Mg}^{2+}$} & \multicolumn{2}{|c|}{$\mathbf{K}^{+}$} & \multicolumn{2}{|c|}{$\mathrm{S}_{-} \mathrm{SO}_{4}{ }^{2-}$} \\
\hline & & $\mathbf{S G}^{(1)}$ & $\mathbf{C G}$ & SG & CG & SG & $\mathbf{C G}$ & SG & CG & SG & $\mathbf{C G}$ \\
\hline \multirow[t]{2}{*}{$\mathrm{m}$} & & & & \multicolumn{6}{|c|}{$\mathrm{mmol}_{\mathrm{c}} \mathrm{dm}^{-3}-$} & \multicolumn{2}{|c|}{$-\mathrm{mgdm} \mathrm{m}^{-3}-$} \\
\hline & & \multicolumn{10}{|c|}{2003 - Antes do $1^{0}$ cultivo (6 meses após aplicação) } \\
\hline \multirow[t]{8}{*}{$0-0,05$} & Calcário, kg ha ${ }^{-1}$ & & & & & & & & & & \\
\hline & 0 & 5,0 & 5,1 & 32,6 & 39,8 & 9,7 & 10,3 & 2,0 & 1,9 & $2,7 \mathrm{~b}$ & $12,5 \mathrm{a}$ \\
\hline & 1.100 & 5,4 & 5,6 & 41,3 & 51,8 & 9,9 & 13,2 & 1,8 & 1,8 & $3,6 \mathrm{~b}$ & $6,3 \mathrm{a}$ \\
\hline & 2.700 & 5,8 & 5,8 & 55,2 & 53,9 & 13,4 & 12,9 & 1,7 & 1,3 & $2,3 \mathrm{a}$ & $4,5 \mathrm{a}$ \\
\hline & 4.300 & 5,9 & 5,9 & 58,4 & 65,4 & 14,0 & 15,0 & 1,9 & 2,4 & $4,0 \mathrm{a}$ & $5,1 \mathrm{a}$ \\
\hline & Média & $5,5 \mathrm{a}^{(2)}$ & $5,6 \mathrm{a}$ & $46,9 \mathrm{a}$ & $52,7 \mathrm{a}$ & $11,7 \mathrm{a}$ & $12,8 \mathrm{a}$ & $1,8 \mathrm{a}$ & $1,9 a$ & - & - \\
\hline & Regressão & \multicolumn{2}{|c|}{$\mathrm{L}^{* *(3)}$} & \multicolumn{2}{|c|}{$\mathrm{L}^{*}$} & \multicolumn{2}{|c|}{$\mathrm{L}^{*}$} & \multicolumn{2}{|c|}{$\mathrm{ns}$} & $\mathrm{ns}$ & $\mathrm{L}^{*}$ \\
\hline & Interação C x G & \multicolumn{2}{|c|}{$\mathrm{ns}$} & & & & & & & & \\
\hline $0,05-0,10$ & Calcário, $\mathrm{kg} \mathrm{ha}^{-1}$ & & & & & & & & & & \\
\hline & 0 & 5,2 & 5,4 & 32,4 & 39,8 & 9,3 & 10,4 & 1,0 & 1,2 & 2,9 & 4,5 \\
\hline & 1.100 & 5,2 & 5,3 & 30,8 & 35,7 & 8,5 & 9,8 & 1,0 & 0,9 & 5,2 & 4,6 \\
\hline & 2.700 & 5,4 & 5,6 & 37,8 & 43,6 & 9,9 & 11,0 & 1,2 & 1,1 & 3,4 & 6,0 \\
\hline & 4.300 & 5,5 & 5,7 & 29,7 & 34,8 & 7,8 & 8,9 & 1,0 & 1,0 & 4,8 & 5,7 \\
\hline & Média & $5,3 a$ & $5,5 \mathrm{a}$ & $32,7 \mathrm{~b}$ & $38,5 \mathrm{a}$ & $8,9 \mathrm{~b}$ & $10,0 \mathrm{a}$ & $1,1 \mathrm{a}$ & $1,0 \mathrm{a}$ & $4,1 \mathrm{a}$ & $5,2 \mathrm{a}$ \\
\hline & Regressão & & & & & & & & & & \\
\hline & Interação C x G & & & & & & & & & & \\
\hline $0,10-0,20$ & Calcário, kg ha ${ }^{-1}$ & & & & & & & & & & \\
\hline & 0 & $4,8 \mathrm{a}$ & $4,9 a$ & 26,3 & 26,4 & $7,7 \mathrm{a}$ & $7,4 \mathrm{a}$ & 0,9 & 0,8 & 4,6 & 12,2 \\
\hline & 1.100 & $4,9 \mathrm{a}$ & $4,8 \mathrm{a}$ & 25,4 & 22,8 & $7,1 \mathrm{a}$ & $7,2 \mathrm{a}$ & 0,8 & 0,8 & 5,1 & 10,8 \\
\hline & 2.700 & $4,8 \mathrm{a}$ & $4,9 \mathrm{a}$ & 23,9 & 22,9 & $6,8 \mathrm{a}$ & $6,6 \mathrm{a}$ & 1,0 & 0,8 & 5,0 & 9,3 \\
\hline & 4.300 & $5,0 \mathrm{a}$ & $5,4 \mathrm{a}$ & 20,2 & 21,2 & $5,9 \mathrm{a}$ & $5,7 \mathrm{a}$ & 0,8 & 0,5 & 5,9 & 9,6 \\
\hline & Média & - & - & $23,9 a$ & $23,3 a$ & - & - & $0,9 a$ & $0,7 \mathrm{a}$ & $5,1 b$ & $10,5 a$ \\
\hline & Regressão & $\mathrm{ns}$ & $\mathrm{L}^{*}$ & & & $\mathrm{~L}^{*}$ & $\mathrm{~ns}$ & & & & \\
\hline & Interação C x G & & & & & & 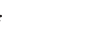 & & & & \\
\hline & & & & 2004 & Antes d & $2^{\circ}$ culti & ro $(18 \mathrm{~m}$ & es após & plicação) & & \\
\hline & Calcário, $\mathrm{kg} \mathrm{ha}^{-1}$ & & & & & & & & & & \\
\hline $0-0,05$ & 0 & 4,6 & 4,8 & 18,1 & 20,4 & 9,0 & 8,3 & 1,6 & 1,5 & 5,2 & 5,7 \\
\hline & 1.100 & 4,8 & 5,0 & 20,2 & 22,6 & 13,8 & 10,7 & 1,0 & 1,1 & 5,8 & 7,5 \\
\hline & 2.700 & 5,3 & 5,7 & 22,8 & 38,2 & 16,7 & 18,8 & 1,4 & 1,6 & 8,3 & 6,5 \\
\hline & 4.300 & 5,7 & 5,8 & 47,4 & 54,8 & 26,4 & 21,8 & 1,2 & 1,0 & 7,1 & 7,7 \\
\hline & Média & $5,1 b$ & $5,3 a$ & $27,1 \mathrm{~b}$ & $34,0 \mathrm{a}$ & $16,8 \mathrm{a}$ & $14,9 \mathrm{a}$ & $1,3 \mathrm{a}$ & $1,3 \mathrm{a}$ & $6,6 \mathrm{a}$ & $6,9 \mathrm{a}$ \\
\hline & Regressão & & & & & & $* *$ & $\mathrm{~ns}$ & $\mathrm{~ns}$ & & \\
\hline & Interação C x G & & & & & & & & & & \\
\hline $0,05-0,10$ & Calcário, kg ha ${ }^{-1}$ & & & & & & & & & & \\
\hline & 0 & 4,6 & 4,8 & $21,9 \mathrm{a}$ & $20,1 \mathrm{a}$ & $10,7 \mathrm{a}$ & $7,9 \mathrm{a}$ & $1,5 \mathrm{a}$ & $0,9 b$ & 4,0 & 6,7 \\
\hline & 1.100 & 4,6 & 4,9 & $20,2 a$ & $22,6 a$ & $11,6 \mathrm{a}$ & $10,7 \mathrm{a}$ & $1,3 \mathrm{a}$ & $1,0 \mathrm{~b}$ & 7,7 & 7,5 \\
\hline & 2.700 & 4,9 & 5,1 & $17,4 \mathrm{a}$ & $23,7 \mathrm{a}$ & $11,7 \mathrm{a}$ & $14,8 \mathrm{a}$ & $1,6 \mathrm{a}$ & $1,5 \mathrm{a}$ & 8,2 & 7,3 \\
\hline & 4.300 & 5,3 & 5,3 & $30,4 a$ & $34,7 \mathrm{a}$ & $17,1 \mathrm{a}$ & $12,0 \mathrm{a}$ & $1,2 \mathrm{a}$ & $1,0 \mathrm{a}$ & 6,7 & 8,4 \\
\hline & Média & $4,9 \mathrm{a}$ & $5,0 \mathrm{a}$ & - & - & - & - & - & - & $6,6 \mathrm{a}$ & $7,4 \mathrm{a}$ \\
\hline & Regressão & & & $Q^{*}$ & $\mathrm{~L}^{* *}$ & $\mathrm{~ns}$ & $\mathrm{~L}^{* *}$ & $\mathrm{~ns}$ & $\mathrm{Q}^{*}$ & & \\
\hline & Interação C x G & & & & & & & & & & \\
\hline $0,10-0,20$ & Calcário, $\mathrm{kg} \mathrm{ha}^{-1}$ & & & & & & & & & & \\
\hline & 0 & 4,5 & 4,6 & 16,8 & 15,1 & 8,7 & 7,6 & $1,2 \mathrm{a}$ & $0,8 \mathrm{~b}$ & $6,6 \mathrm{a}$ & $7,0 \mathrm{a}$ \\
\hline & 1.100 & 4,4 & 4,6 & 12,5 & 12,4 & 7,4 & 7,0 & $1,0 \mathrm{a}$ & $1,1 \mathrm{a}$ & $11,3 \mathrm{a}$ & $9,0 \mathrm{a}$ \\
\hline & 2.700 & 4,5 & 4,6 & 10,2 & 14,4 & 8,6 & 6,2 & $1,6 \mathrm{a}$ & $1,4 \mathrm{a}$ & $6,9 a$ & $12,0 \mathrm{a}$ \\
\hline & 4.300 & 4,8 & 4,8 & 16,7 & 24,7 & 7,8 & 7,5 & $1,0 \mathrm{a}$ & $0,9 \mathrm{a}$ & $8,8 \mathrm{a}$ & $13,2 \mathrm{a}$ \\
\hline & Média & $4,6 \mathrm{a}$ & $4,7 \mathrm{a}$ & $14,0 \mathrm{a}$ & $16,6 \mathrm{a}$ & $8,1 \mathrm{a}$ & $7,1 \mathrm{a}$ & - & - & - & - \\
\hline & Regressão & & & & & & & $\mathrm{ns}$ & $Q^{* *}$ & $\mathrm{~ns}$ & $\mathrm{~L}^{*}$ \\
\hline & Interação C x G & & & & & & & & & & \\
\hline
\end{tabular}

(1) SG indica os tratamentos sem aplicação de gesso e CG os tratamentos com aplicação de gesso (2.100 kg ha $\left.{ }^{-1}\right)$. ${ }^{(2)}$ Médias seguidas de letras distintas, na linha, dentro de cada variável, diferem entre si pelo teste $\mathrm{t}(\mathrm{p}=0,05)$. ${ }^{(3)} \mathrm{L}$ e $\mathrm{Q}$ representam efeito linear e quadrático pela regressão polinomial, respectivamente. ns, * e ** são não-significativo e significativos a 5 e $1 \%$ pelo teste t, respectivamente. 
Quadro 2. Teores médios de N, P, K, Ca, Mg, S, Cu, Fe, Mn e Zn na folha bandeira de aveia-preta, em função da aplicação de calcário e gesso em superfície na implantação do sistema plantio direto

\begin{tabular}{|c|c|c|c|c|c|c|c|c|c|c|}
\hline Tratamento & $\mathbf{N}$ & $\mathbf{P}$ & $\mathbf{K}$ & $\mathbf{C a}$ & $\mathrm{Mg}$ & $\mathbf{S}$ & $\mathrm{Cu}$ & $\mathrm{Fe}$ & Mn & $\mathrm{Zn}$ \\
\hline \multirow[b]{2}{*}{ Calcário, kg ha ${ }^{-1}$} & & & - g & $r^{-1}$ & & 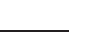 & \multicolumn{4}{|c|}{$\mathrm{mg} \mathrm{kg}^{-1}$} \\
\hline & & & & & & 2003 & & & & \\
\hline 0 & 45,6 & 2,4 & 7,9 & 5,3 & 3,7 & 3,3 & 18,0 & 222,4 & 168,7 & 20,9 \\
\hline 1.100 & 47,5 & 2,4 & 8,3 & 8,0 & 3,3 & 3,0 & 7,2 & 126,4 & 178,9 & 21,8 \\
\hline 2.700 & 45,9 & 2,6 & 8,7 & 6,6 & 3,2 & 2,9 & 5,4 & 111,2 & 161,9 & 20,1 \\
\hline 4.300 & 46,1 & 2,5 & 7,7 & 7,1 & 3,3 & 2,8 & 5,5 & 119,4 & 172,8 & 24,3 \\
\hline Regressão & $\mathrm{ns}$ & $\mathrm{ns}$ & $\mathrm{Q}^{(1)}$ & $\mathrm{ns}$ & - & - & $\mathrm{Q}^{(2)}$ & $\mathrm{Q}^{(3)}$ & $\mathrm{ns}$ & $\mathrm{ns}$ \\
\hline CV (\%) & 9,6 & 9,7 & 10,4 & 27,5 & 18,9 & 20,0 & 43,1 & 30,8 & 29,0 & 30,8 \\
\hline Sem gesso & $45,6 \mathrm{a}$ & $2,4 \mathrm{a}$ & $8,0 \mathrm{a}$ & $6,3 \mathrm{a}$ & 3,4 & 2,2 & $8,6 \mathrm{a}$ & $157,2 \mathrm{a}$ & $173,1 \mathrm{a}$ & $23,1 \mathrm{a}$ \\
\hline Com gesso & $46,9 \mathrm{a}$ & $2,5 \mathrm{a}$ & $8,3 \mathrm{a}$ & $7,2 \mathrm{a}$ & 3,4 & 3,9 & $9,4 \mathrm{a}$ & $132,5 \mathrm{a}$ & $168,1 \mathrm{a}$ & $20,4 \mathrm{a}$ \\
\hline CV (\%) & 8,1 & 5,6 & 23,1 & 18,6 & 13,9 & 10,0 & 31,3 & 34,8 & 21,9 & 30,6 \\
\hline Interação C x G & $\mathrm{ns}$ & $\mathrm{ns}$ & $\mathrm{ns}$ & $\mathrm{ns}$ & $*$ & $*$ & $\mathrm{~ns}$ & $\mathrm{~ns}$ & $\mathrm{~ns}$ & $\mathrm{~ns}$ \\
\hline Calcário, kg ha ${ }^{-1}$ & & & & & & 2004 & & & & \\
\hline 0 & 46,8 & 2,4 & 9,5 & 9,6 & 2,1 & 5,4 & 32,3 & 159,5 & 383,5 & 44,5 \\
\hline 1.100 & 46,9 & 2,4 & 9,8 & 8,9 & 1,9 & 5,9 & 37,3 & 148,8 & 413,5 & 38,8 \\
\hline 2.700 & 46,1 & 2,7 & 9,5 & 9,2 & 2,1 & 5,7 & 31,7 & 144,0 & 330,3 & 40,2 \\
\hline 4.300 & 46,6 & 2,5 & 9,1 & 9,5 & 2,1 & 5,5 & 26,5 & 136,3 & 361,5 & 34,5 \\
\hline Regressão & $\mathrm{ns}$ & $\mathrm{L}^{(4)}$ & ns & $\mathrm{ns}$ & $\mathrm{ns}$ & $\mathrm{ns}$ & $\mathrm{ns}$ & $\mathrm{L}^{(5)}$ & $\mathrm{ns}$ & $\mathrm{ns}$ \\
\hline CV (\%) & 8,2 & 5,9 & 14,8 & 16,8 & 9,2 & 25,6 & 47,9 & 16,7 & 14,6 & 45,9 \\
\hline Sem gesso & $46,6 \mathrm{a}$ & $2,5 \mathrm{a}$ & $9,4 \mathrm{a}$ & $9,1 \mathrm{a}$ & $2,1 \mathrm{a}$ & $4,7 \mathrm{~b}$ & $28,4 b$ & $145,2 \mathrm{a}$ & $370,7 \mathrm{a}$ & $41,0 \mathrm{a}$ \\
\hline Com gesso & $46,1 \mathrm{a}$ & $2,5 \mathrm{a}$ & $9,5 \mathrm{a}$ & $9,5 \mathrm{a}$ & $2,0 \mathrm{a}$ & $6,6 \mathrm{a}$ & $35,5 \mathrm{a}$ & $149,0 \mathrm{a}$ & $373,6 \mathrm{a}$ & $38,0 \mathrm{a}$ \\
\hline $\mathrm{CV}(\%)$ & 5,7 & 6,6 & 10,2 & 9,6 & 7,0 & 12,6 & 27,3 & 9,9 & 12,0 & 16,0 \\
\hline Interação $\mathrm{C} \times \mathrm{G}$ & $\mathrm{ns}$ & $\mathrm{ns}$ & $\mathrm{ns}$ & $\mathrm{ns}$ & $\mathrm{ns}$ & $\mathrm{ns}$ & $\mathrm{ns}$ & $\mathrm{ns}$ & $\mathrm{ns}$ & $\mathrm{ns}$ \\
\hline
\end{tabular}

${ }^{(1)} \mathrm{y}=7,80+0,00085 \mathrm{x}-0,0000001 \mathrm{x}^{2} \mathrm{R}^{2}=0,89^{*} \cdot{ }^{(2)} \mathrm{y}=17,21-0,009 \mathrm{x}+0,000002 \mathrm{x}^{2} \mathrm{R}^{2}=0,93^{* *} \cdot{ }^{(3)} \mathrm{y}=215,50-0,082 \mathrm{x}+0,000014 \mathrm{x}^{2} \mathrm{R}^{2}$ $=0,93^{* *} \cdot{ }^{(4)} \mathrm{y}=2,41+0,000041 \mathrm{x} \mathrm{R}^{2}=0,42^{*} .{ }^{(5)} \mathrm{y}=157,34-0,051 \mathrm{x} \mathrm{R}^{2}=0,95^{*}$. Médias seguidas de letras distintas, na coluna, para o fator gesso, diferem entre si pelo teste $\mathrm{t}(\mathrm{p}=0,05)$. Para interação e para regressão: ns, * e ** são não-significativo e significativo a $5 \%$ pelo teste $t$, respectivamente.

relaciona positivamente com o aumento do $\mathrm{pH}$, principalmente nas camadas superficiais. Esse efeito se deve à maior solubilização de $\mathrm{P}$ ligado a $\mathrm{Fe}$ e $\mathrm{Al}$, com a elevação do $\mathrm{pH}$, o que proporciona maior aproveitamento do $\mathrm{P}$ pela cultura. No entanto, comparando os teores desse nutriente na folha bandeira (Quadro 2) com a faixa considerada adequada para a aveia (Kelling \& Fixen, 1992; Cantarella et al., 1996), verifica-se que em todos os tratamentos os valores estão acima do limite mínimo de suficiência.

A aplicação de calcário em superfície teve efeito significativo sobre teor de $\mathrm{K}$ na folha bandeira, no primeiro ano de cultivo, proporcionando efeito quadrático em função do aumento das doses de calcário (Quadro 2). De acordo com Nogueira \& Mozeto (1990), pode haver liberação de $\mathrm{K}$ dos sítios de troca para a solução do solo, dependendo do aumento nos teores de Ca trocável no solo. Porém, vale destacar que, nos dois anos de cultivo, em todos os tratamentos, os teores de $\mathrm{K}$ encontravam-se abaixo da faixa considerada adequada para a aveia (Kelling \& Fixen, 1992; Cantarella et al., 1996), o que pode ter sido acarretado pelos elevados teores de cálcio no solo (Quadro 1). A redução da relação $\mathrm{K} /(\mathrm{Ca}+\mathrm{Mg})$ pode ter inibido a absorção de K, já que em todos os tratamentos os teores de Ca nas folhas estavam acima daqueles considerados adequados pela maioria dos especialistas (Cantarella et al., 1996). O excesso de Ca e, em menor escala, o de $\mathrm{Mg}$ determinam menor absorção de $\mathrm{K}$, já que o Ca e o Mg competem com o $\mathrm{K}$ pelos sítios de absorção (Malavolta, 1980). Caires et al. (2002a) verificaram redução do teor de $\mathrm{K}$ no tecido foliar do milho e aumento dos de $\mathrm{Ca}$ e $\mathrm{Mg}$, em função da aplicação superfícial de calcário dolomítico, sem, no entanto, afetar a produção de grãos. Büll et al. (1993) verificaram que a redução nos valores da relação $\mathrm{K} /(\mathrm{Ca}+\mathrm{Mg})$, tanto em solos de textura média quanto nos argilosos, proporcionou deficiência de potássio em Panicum maximum L. cv. Tobiatã. Nakagawa \& Rosolem (2005) também obtiveram teores de $\mathrm{K}$ abaixo da faixa considerada adequada nas folhas bandeira da aveia-preta cultivada em Botucatu (SP), mesmo com a aplicação de $40 \mathrm{~kg} \mathrm{ha}^{-1}$ de $\mathrm{K}_{2} \mathrm{O}$.

Apesar de terem aumentado os teores de Ca nas camadas mais superficiais do solo (Quadro 1), tanto a calagem quanto a gessagem não afetaram o teor desse elemento na planta (Quadro 2). A ausência de efeito no teor de Ca pode estar relacionada aos altos teores desse nutriente no solo, mesmo no tratamento testemunha. Tiritan (2001) e Caires et al. (2004) também não 
verificaram aumento no teor de Ca nas folhas do milho em função da calagem, tanto incorporada quanto em superfície.

Nos tratamentos que não receberam gesso, o aumento das doses de calcário promoveu decréscimo dos teores de Mg na folha bandeira da aveia-preta, enquanto, nos que receberam gesso, a calagem não teve efeito no primeiro ano de cultivo (Figura 2). Notase que houve grande redução no teor foliar de $\mathrm{Mg}$ em função da aplicação de gesso no tratamento que não recebeu calcário em superfície, indicando que o gesso reduziu a absorção de $\mathrm{Mg}$. Este comportamento pode estar relacionado com o aumento da relação $\mathrm{Ca} / \mathrm{Mg}$ no solo, proporcionado pela aplicação de gesso (Quadro 1). Porém, em todos os tratamentos, os teores de Mg estavam dentro da faixa considerada adequada (Cantarella et al., 1996), o que provavelmente é conseqüência dos altos teores desse nutriente no solo, mesmo onde não foi aplicado calcário. No segundo ano de cultivo, não foi observado efeito dos tratamentos na absorção de Mg pela aveia-preta.

A aplicação de gesso afetou os teores de S, aumentando-os na folha bandeira da aveia-preta nos dois anos de cultivo (Quadro 2). Deve-se ressaltar que o gesso é excelente fonte desse nutriente (Caires et al., 1998). Caires et al. (2001,2002b) verificaram aumento linear no teor de $\mathrm{S}$ nas folhas de cevada e

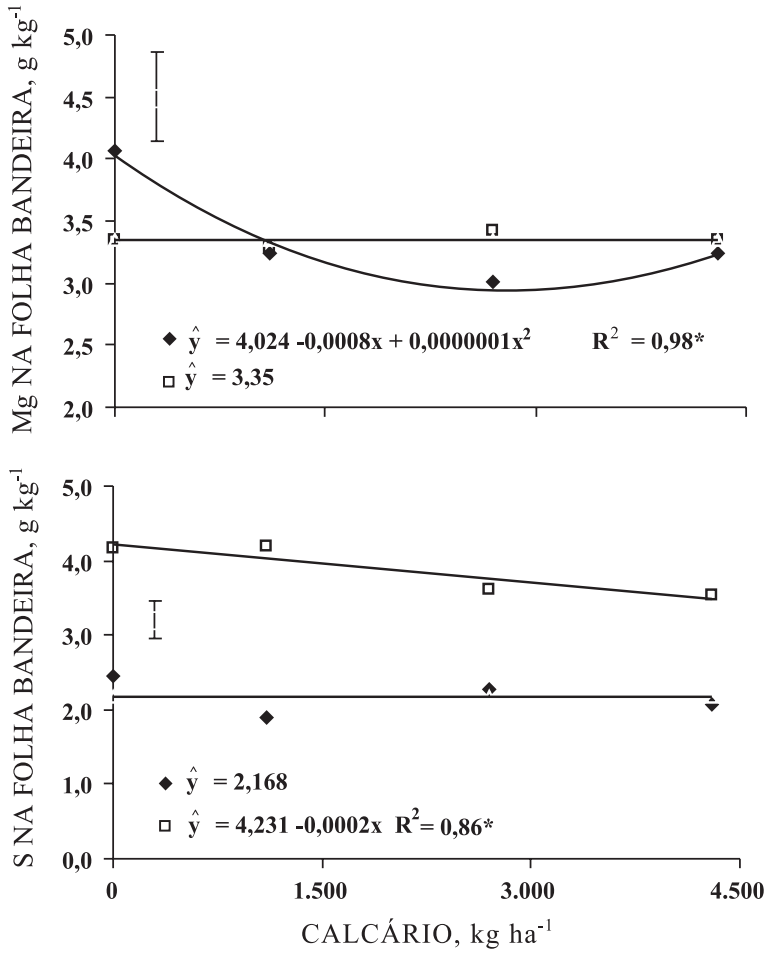

Figura 2. Teores Mg e S na folha bandeira de aveiapreta em função da aplicação de calcário em superfície, sem ( $($ ) e com ( $\square$ ) a aplicação de gesso, no ano de 2003. * é significativo a $5 \%$ pelo teste t. Barras verticais indicam o valor de DMS pelo teste $t(p=0,05)$. trigo, respectivamente, como conseqüência da elevação dos teores de $\mathrm{S}_{-} \mathrm{SO}_{4}{ }^{2-}$ no solo, em função da aplicação de gesso. Em 2003, a calagem proporcionou redução na absorção de $\mathrm{S}$ nos tratamentos que receberam aplicação de gesso, mas não interferiu quando o gesso não foi aplicado (Figura 2). Os teores de S na folha bandeira das plantas oriundas de todos os tratamentos estiveram, em 2003, na faixa considerada adequada para a aveia, 1,5-4,0 $\mathrm{g} \mathrm{kg}^{-1}$ (Cantarella et al., 1996) e acima dela em 2004. A maior disponibilidade hídrica, no segundo ano de cultivo (Figura 1), pode ter favorecido o crescimento radicular, promovendo exploração de maior volume de solo, aumentando a absorção de enxofre de camadas mais profundas.

Dentre os micronutrientes analisados na folha bandeira, constatou-se que a calagem em superfície promoveu redução nos teores de $\mathrm{Cu}$ e Fe no primeiro ano, e de Fe no segundo ano de cultivo, o que pode ser explicado pela diminuição da disponibilidade desses nutrientes pela elevação do $\mathrm{pH}$ do solo (Quadro 1), principalmente na camada superficial (Harmsen \& Vlek, 1985). Além disso, os altos teores de Ca na folha bandeira da aveia-preta indicam que a elevada disponibilidade de $\mathrm{Ca}$ no solo, proporcionada pela aplicação de calcário, pode ter inibido a absorção de Fe pelas plantas, já que esses elementos competem pelos mesmos sítios de absorção (Fageria, 2001). A diminuição na produção de muitas culturas, quando submetidas à calagem, tem sido associada com a redução na disponibilidade de $\mathrm{Cu}, \mathrm{Fe}$, Zn e Mn no solo (Sumner et al., 1978). No entanto, a calagem não teve efeito sobre a absorção de Mn e Zn pela cultura da aveia-preta. Quaggio et al. (1993) também não observaram redução nos teores foliares de Mn e Zn da soja em função da calagem.

A aplicação de gesso não afetou os teores dos micronutrientes analisados no primeiro cultivo (Quadro 2), porém aumentou o teor de $\mathrm{Cu}$ no segundo ano. No entanto, os teores de todos os micronutrientes estavam na faixa ou acima do considerado adequado para aveia (Cantarella et al., 1996). Nakagawa \& Rosolem (2005) também verificaram teores de Fe e Mn na folha bandeira acima dos considerados adequados por Cantarella et al. (1996). De acordo com Kelling \& Fixen (1992), essa variação na faixa de teores para micronutrientes em folhas de aveia justifica a necessidade de maior número de trabalhos sobre o assunto.

Considerando-se os teores de nutrientes na folha bandeira, na média dos tratamentos, obteve-se a seguinte ordem: $\mathrm{N}>\mathrm{K}>\mathrm{Ca}>\mathrm{Mg}>\mathrm{S}>\mathrm{P}>\mathrm{Mn}>\mathrm{Fe}$ $>\mathrm{Zn}>\mathrm{Cu}$ no primeiro ano, e $\mathrm{N}>\mathrm{K}>\mathrm{Ca}>\mathrm{S}>\mathrm{P}>$ $\mathrm{Mg}>\mathrm{Mn}>\mathrm{Fe}>\mathrm{Zn}>\mathrm{Cu}$ no segundo (Quadro 2). A ordem observada no primeiro ano é discrepante, porém a de 2004 é idêntica à relatada por Nakagawa \& Rosolem (2005), para aveia-preta, enquanto as faixas de teores adequadas para aveia indicam a seqüência $\mathrm{N}>\mathrm{K}>\mathrm{Ca}>\mathrm{P}>\mathrm{Mg}>\mathrm{S}>\mathrm{Fe}>\mathrm{Mn}>\mathrm{Zn}>\mathrm{Cu}$ (Cantarella et al., 1996). Essa variação nos resultados 
pode ser explicada pelas diferenças de manejo da cultura, níveis e quantidades de nutrientes aplicados por meio de adubação e condições climáticas de cada local e época de cultivo.

A altura da planta foi influenciada pela interação entre calcário e gesso no primeiro ano de cultivo (Quadro 3). Na presença de gesso, a calagem promoveu incrementos maiores na altura da planta (Figura 3). No segundo ano, a altura das plantas não sofreu efeito dos tratamentos, porém as plantas de aveia-preta apresentaram maior altura do que no primeiro ano. Tal fato deve estar relacionado à maior disponibilidade hídrica ocorrida em 2004 (Figura 1), o que favoreceu o crescimento da cultura. Entretanto, foi verificado acamamento de plantas em todos os tratamentos, condição que não ocorreu em 2003. De modo geral, os valores de altura de planta observados no segundo ano foram semelhantes aos verificados por Nakagawa et al. (2000) na mesma condição de clima e solo.

Quanto aos componentes da produção, no primeiro ano de cultivo, o número de panículas por metro quadrado foi influenciado pela interação entre os fatores estudados (Quadro 3), e a calagem na ausência da aplicação de gesso promoveu efeito quadrático para essa variável (Figura 3). A aplicação de gesso na ausência de calagem pode ter favorecido o crescimento radicular da aveia-preta, contribuindo para maior absorção de água e nutrientes pela cultura, e conseqüentemente para a transformação de mais gemas vegetativas em reprodutivas, o que resultou na formação de mais panículas.

Na segunda safra, a aplicação de calcário promoveu aumento linear no número de espiguetas por panícula e a massa de 1.000 grãos foi incrementada pela aplicação de gesso. No entanto, esses efeitos foram pouco expressivos (Quadro 3).

A produtividade de grãos foi afetada pela interação calagem e gessagem no primeiro ano de cultivo (Quadro 3). Nos tratamentos que não receberam gesso, a aplicação de calcário proporcionou acréscimo linear na produtividade (Figura 3). Já na presença de gesso, a resposta da aveia-preta à calagem foi quadrática, com a dose de $2.860 \mathrm{~kg} \mathrm{ha}^{-1}$, tendo proporcionado a produtividade máxima estimada. Os resultados podem ser explicados pelo fato de que a calagem e a gessagem melhoraram as condições do solo, provavelmente, favorecendo o crescimento radicular e a absorção de água e nutrientes em períodos de deficiência hídrica e, conseqüentemente, proporcionando aumento na produtividade (Caires et

Quadro 3. Altura da planta, número de panículas $\mathrm{m}^{2}$, número de espiguetas por panícula, fertilidade das espiguetas, massa de 1.000 grãos e produtividade de aveia-preta, em função da aplicação de calcário e gesso em superfície na implantação do sistema plantio direto

\begin{tabular}{|c|c|c|c|c|c|c|}
\hline Tratamento & $\begin{array}{l}\text { Altura da } \\
\text { planta }\end{array}$ & $\begin{array}{c}\text { Número de } \\
\text { panículas por } \\
\mathbf{m}^{-2}\end{array}$ & $\begin{array}{c}\text { Número de } \\
\text { espiguetas por } \\
\text { panicula }^{-1}\end{array}$ & $\begin{array}{l}\text { Fertilidade } \\
\text { das } \\
\text { espiguetas }\end{array}$ & $\begin{array}{l}\text { Massa de } \\
1.000 \text { grãos }\end{array}$ & $\begin{array}{l}\text { Produtividade } \\
\text { de grãos }\end{array}$ \\
\hline & $\mathrm{cm}$ & & & $\%$ & $\mathrm{~g}$ & $\mathrm{~kg} \mathrm{ha}^{-1}$ \\
\hline Calcário, kg ha ${ }^{-1}$ & & & & 2003 & & \\
\hline 0 & 110,9 & 242,8 & 39,6 & 76,0 & 16,5 & 893 \\
\hline 1.100 & 112,5 & 238,8 & 40,4 & 72,5 & 15,8 & 977 \\
\hline 2.700 & 117,4 & 300,2 & 38,7 & 70,5 & 17,1 & 1.409 \\
\hline 4.300 & 123,1 & 251,7 & 42,4 & 76,0 & 17,5 & 1.294 \\
\hline Regressão & - & & $\mathrm{ns}$ & $\mathrm{ns}$ & $\mathrm{ns}$ & - \\
\hline CV (\%) & 5,5 & 15,3 & 20,8 & 18,8 & 8,9 & 29,5 \\
\hline Sem gesso & 114,6 & 250,4 & $41,1 \mathrm{a}$ & $74,6 \mathrm{a}$ & $16,5 \mathrm{a}$ & 1.074 \\
\hline Com gesso & 117,4 & 266,3 & $39,4 \mathrm{a}$ & $72,9 \mathrm{a}$ & $16,8 \mathrm{a}$ & 1.213 \\
\hline CV $(\%)$ & 2,6 & 10,2 & 10,5 & 11,5 & 10,0 & 20,1 \\
\hline Interação C x G & * & * & $\mathrm{ns}$ & $\mathrm{ns}$ & $\mathrm{ns}$ & * \\
\hline Calcário, kg há ${ }^{-1}$ & & & & 2004 & & \\
\hline 0 & 158,2 & 420,6 & 60,7 & 91,8 & 20,3 & 1.575 \\
\hline 1.100 & 160,6 & 433,1 & 60,1 & 87,9 & 21,1 & 1.758 \\
\hline 2.700 & 159,0 & 425,8 & 61,7 & 89,6 & 20,7 & 1.281 \\
\hline 4.300 & 160,7 & 417,3 & 69,9 & 91,2 & 20,7 & 1.702 \\
\hline Regressão & $\mathrm{ns}$ & $\mathrm{ns}$ & $\mathrm{L}^{(1)}$ & $\mathrm{ns}$ & $\mathrm{ns}$ & $\mathrm{ns}$ \\
\hline CV (\%) & 4,2 & 13,0 & 9,6 & 4,5 & 6,4 & 15,6 \\
\hline Sem gesso & $159,5 \mathrm{a}$ & $413,7 \mathrm{a}$ & $63,5 \mathrm{a}$ & $90,0 \mathrm{a}$ & $20,2 b$ & $1.565 \mathrm{a}$ \\
\hline Com gesso & $159,8 \mathrm{a}$ & $434,8 \mathrm{a}$ & $62,7 \mathrm{a}$ & $90,2 \mathrm{a}$ & $21,2 \mathrm{a}$ & $1.592 \mathrm{a}$ \\
\hline CV $(\%)$ & 2,9 & 14,0 & 12,4 & 4,3 & 4,6 & 10,0 \\
\hline Interação $\mathrm{C} \times \mathrm{G}$ & $\mathrm{ns}$ & $\mathrm{ns}$ & $\mathrm{ns}$ & $\mathrm{ns}$ & $\mathrm{ns}$ & $\mathrm{ns}$ \\
\hline
\end{tabular}

${ }^{(1)} \mathrm{y}=58,87+0,0021 \mathrm{x} \mathrm{R}^{2}=0,74^{*}$. Médias seguidas de letras distintas, na coluna, para o fator gesso, diferem entre si pelo teste $\mathrm{t}$ $(p=0,05)$. Interação: $n s=$ não significativo $e^{*}=$ Significativo, pelo teste $t(p=0,05)$. Para interação e para regressão: ns, * e ** são não-significativo e significativo a $5 \%$ pelo teste $t$, respectivamente. 

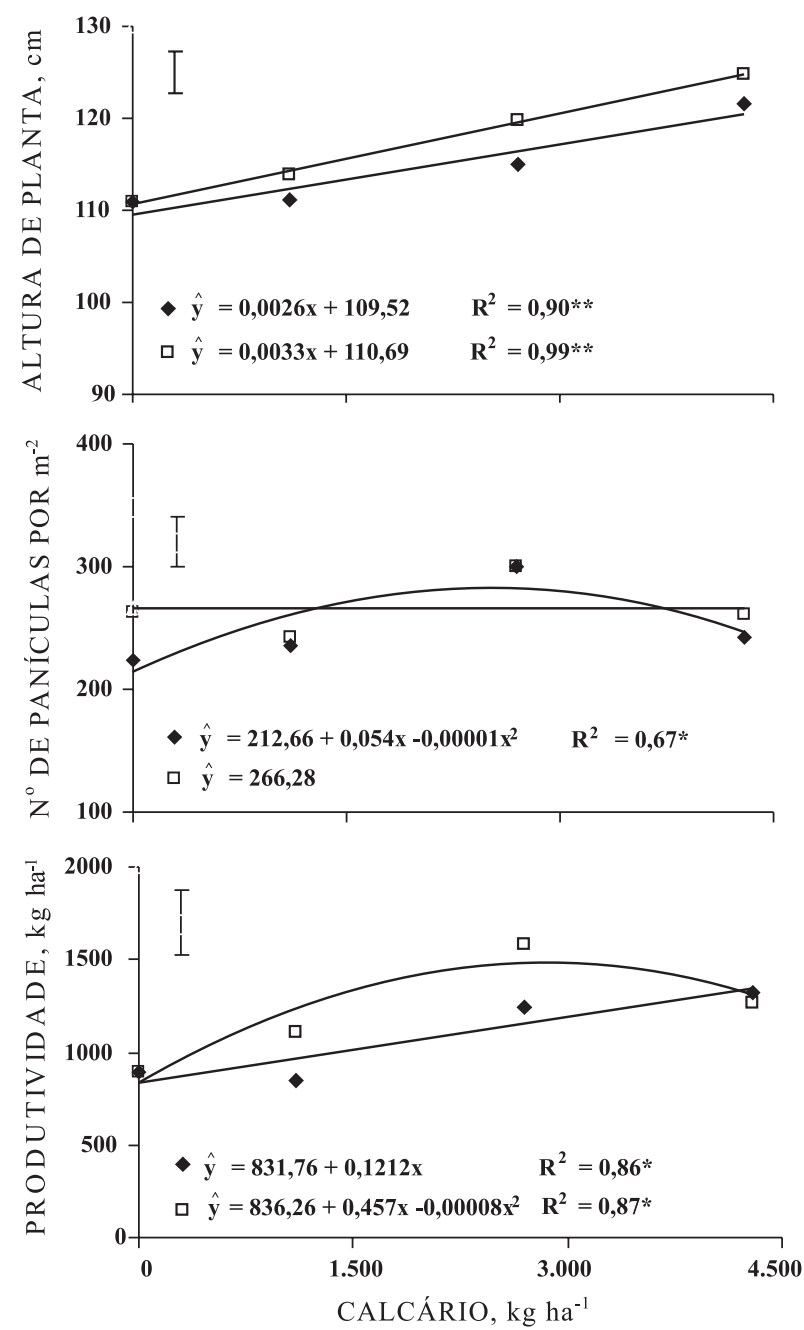

Figura 3. Altura de planta, número de panícula por $\mathrm{m}^{-2}$ e produtividade de grãos de aveia-preta em função da calagem em superfície, $\operatorname{sem}(\Delta)$ e com ( $\square$ ) a aplicação de gesso, no ano de 2003 . * e ** são significativos a 5 e $1 \%$ pelo teste $t$. Barras verticais indicam o valor de DMS pelo teste $t$ $(\mathrm{p}=0,05)$.

al., 2001). Além disso, é de grande importância à elevação da disponibilidade de $\mathrm{S}_{-} \mathrm{SO}_{4}{ }^{2-}$ no solo, principalmente na fase de enchimento de grãos, para a obtenção de elevada produtividade de grãos, já que o enxofre é relativamente imóvel na planta (Malavolta et al., 1997; Caires et al., 2001, 2002b). Respostas do milho e da cevada à aplicação de gesso, em decorrência do fornecimento de enxofre, da melhoria do teor de $\mathrm{Ca}$ trocável e do aumento da relação $\mathrm{Ca} / \mathrm{Mg}$ no solo, também foram observadas por Caires et al. (1999) e Caires et al. (2001), respectivamente.

No segundo ano de cultivo, os fatores estudados não afetaram a produtividade de grãos (Quadro 3). A ausência de efeito e a maior produtividade média da aveia-preta, no segundo ano, podem estar relacionadas com a maior disponibilidade hídrica (Figura 1). Caires et al. (2001) e Caires et al. (2002b) não verificaram efeito da calagem superficial na produtividade de cevada e trigo em plantio direto, respectivamente. Esses autores observaram aumento de produtividade dessas culturas com a aplicação de gesso em superfície. No entanto, é importante destacar que os autores utilizaram elevadas doses de gesso agrícola (até $9.000 \mathrm{~kg} \mathrm{ha}^{-1}$ ) e que nos dois casos houve períodos de deficiência hídrica durante o desenvolvimento das culturas.

De maneira geral, apesar da acidez do solo não ser elevada e dos altos teores de Ca e Mg (Raij et al., 1996), principalmente nas camadas mais superficiais, mesmo nos tratamentos que não receberam aplicação de corretivos (Quadro 1), em ano com deficiência hídrica, a aplicação de calcário e gesso, em superfície, pode favorecer a nutrição e a produtividade da aveia-preta cultivada no inverno, provavelmente por melhorar as condições químicas do solo e favorecer a exploração de camadas mais profundas do solo pelas raízes.

\section{CONCLUSÕES}

1. O aumento no teor de Ca no solo, provocado pela aplicação de calcário e gesso, diminuiu o teor de $\mathrm{Mg}$ na folha bandeira da aveia-preta em ano com deficiência hídrica.

2. A aplicação de calcário em superfície aumentou os teores de $\mathrm{K}$ e reduziu os de $\mathrm{Cu}$ e Fe na folha bandeira da aveia-preta.

3. A aplicação de gesso agrícola em superfície aumentou o teor de $\mathrm{S}$ na folha bandeira da aveia-preta.

4. A calagem em superfície aumentou a produtividade de grãos da aveia-preta em ano com deficiência hídrica, com efeitos mais pronunciados na presença de gesso.

\section{AGRADECIMENTO}

À FAPESP pela concessão de bolsa de doutorado ao primeiro autor.

\section{LITERATURA CITADA}

BAIER, A.C.; FLOSS, E.L. \& AUDE, M.I.S. As lavouras de inverno. Rio de Janeiro, Globo, 1988. 172p.

BALBINO, L.C.; MOREIRA, J.A.A.; SILVA, J.G.; OLIVEIRA, E.F. \& OLIVEIRA, I.P. Plantio direto. In: ARAUJO, R.S.; RAVA, C.A.; STONE, L.F. \& ZIMMERMANN, M.J.O. Cultura do feijoeiro comum no Brasil. Piracicaba, Potafós, 1996. p.301-352.

BARIZON, R.R.M. Calagem na superfície para a cultura da soja, em semeadura direta sobre Brachiaria brizantha. Botucatu, Universidade Estadual Paulista, 2001. 88p. (Tese de Mestrado) 
BOHNEN, H. Acidez do solo: origem e evolução. In: KAMINSKI, J., coord. Uso de corretivos da acidez do solo no plantio direto. Pelotas, Núcleo Regional Sul da Sociedade Brasileira de Ciência do Solo, 2000. p.9-19 (Boletim, 4)

BÜLL, L.T.; BOARETTO, A.E.; MELLO, F.A.F. \& SOARES, E. Influência da relação $\mathrm{K} /(\mathrm{Ca}+\mathrm{Mg})$ do solo na produção de matéria seca e na absorção de potássio por gramínea e leguminosa forrageiras. II. Absorção de potássio em função da relação $\mathrm{K} /(\mathrm{Ca}+\mathrm{Mg})$ no complexo de troca do solo. Científica, 21:67-75, 1993.

CAIRES E.F.; BARTH, G.; GARBUIO, F.J. \& KUSMAN, M.T. Correção da acidez do solo, crescimento radicular e nutrição do milho de acordo com a calagem na superfície em sistema de plantio direto. R. Bras. Ci. Solo, 26:10111022, 2002a.

CAIRES, E.F. \& FONSECA, A.F. Absorção de nutrientes pela soja cultivada no sistema de plantio direto em função de calagem na superfície. Bragantia, 59:213-220, 2000.

CAIRES, E.F.; ALLEONI, L.R.F.; CAMBRI, M.A. \& BARTH, G. Surface application of lime for crop grain prodution under a no-till system. Agron. J., 97:791-798, 2005.

CAIRES, E.F.; BLUM, J.; BARTH, G.; GARBUIO, F.J. \& KUSMAN, M.T. Alterações químicas do solo e resposta da soja ao calcário e gesso aplicados na implantação do sistema de plantio direto. R. Bras. Ci. Solo, 27:275-286, 2003.

CAIRES, E.F.; CHUEIRI, W.A.; MADRUGA, E.F. \& FIGUEIREDO, A. Alterações de características químicas do solo e resposta da soja ao calcário e gesso aplicados na superfície em sistema de cultivo sem preparo de solo. R. Bras. Ci. Solo, 22:27-34, 1998.

CAIRES, E.F.; FELDHAUS, I.C. \& BLUM, J. Crescimento radicular e nutrição da cevada em função da calagem e aplicação de gesso. Bragantia, 60:213-223, 2001.

CAIRES, E.F.; FELDHAUS, I.C.; BARTH, G. \& GARBUIO, F.J. Lime and gypsum application on the wheat crop. Sci. Agric., 59:357-364, 2002b.

CAIRES, E.F.; FONSECA, A.F.; MENDES, J.; CHUEIRI, W. \& MADRUGA, E.F. Produção de milho, trigo e soja em função das alterações das características químicas do solo pela aplicação de calcário e gesso na superfície, em sistema de plantio direto. R. Bras. Ci. Solo, 23:315-327, 1999.

CAIRES, E.F.; KUSMAN, M.T.; BARTH, G.; GARBUIO, F.J. \& PADILHA, J.M. Alterações químicas do solo e resposta do milho à calagem e aplicação de gesso. R. Bras. Ci. Solo, 28:125-136, 2004.

CALEGARI, A. Rotação de culturas e plantas de cobertura como sustentáculo do sistema de plantio direto. In CONGRESSO BRASILEIRO DE CIÊNCIA DO SOLO, Londrina, 2001. Anais. Londrina, Sociedade Brasileira de Ciência do Solo, 2001. p.241.

CANTARELlA, H.; RAIJ, B.van \& CAMARGO, C.E.O Cereais. In: RAIJ, B.van; CANTARELLA, H.; QUAGGIO, J.A. \& FURLANI, A.M.C., eds. Recomendações de adubação e calagem para o Estado de São Paulo. Campinas, Instituto Agronômico, 1996. p.45-47.
DERPSCH, R. \& CALEGARI, A. Plantas para adubação verde de inverno. Londrina, Instituto Agronômico do Paraná, 1992. 80p. (Circular, 73)

EMPRESA BRASILEIRA DE PESQUISA AGROPECUÁRIA EMBRAPA. Centro Nacional de Pesquisa de Solos. Manual de métodos de análise de solo. 2.ed. Brasília, Embrapa-CNPS, 1997. 212p. (Documentos, 1)

FAGERIA, V.D. Nutrient interactions in crop plants. J. Plant Nutr., 24:1269-1290, 2001.

HARMSEN, K. \& VLEK, P.L.G. The chemistry of micronutrients in soil. Fert. Res., 7:1-42, 1985.

HERNANI, L.C.; KURIHARA, C.H. \& SILVA, W.M. Sistema de manejo do solo e perdas de nutrientes e matéria orgânica por erosão. R. Bras. Ci. Solo, 23:145-154, 1999.

KELLING, K.A. \& FIXEN, P.E. Soil and nutrient requirements for oat production. In: MARSHALL, H.G. \& SORRELLS, M.E. Oat science and technology. Madison, American Society of Agronomy, Crop Science Society of America, 1992. p.165-190.

LIMA, E.V. Plantas de cobertura e calagem superficial na fase de implantação do sistema de plantio direto em região de inverno seco. Botucatu, Universidade Estadual Paulista, 2004. 125p. (Tese de Doutorado)

MALAVOLTA, E. Elementos de nutrição mineral de plantas. Piracicaba, Agronômica Ceres, 1980. 251p.

MALAVOLTA, E.; VITTI, G.C. \& OLIVEIRA, S.A. Avaliação do estado nutricional de plantas: princípios e aplicações. 2.ed. Piracicaba, Potafos, 1997. 319p.

MELLO, J.C.A. Granulometria e doses de calcário dolomítico em sistema de plantio convencional e direto, cultivado com milho. Botucatu, Universidade Estadual Paulista, 2001. 94p. (Tese de Mestrado)

NAKAGAWA, J. \& ROSOLEM, C.A. Teores de nutrientes na folha e nos grãos de aveia-preta em função da adubação com fósforo e potássio. Bragantia, 64:411-445, 2005.

NAKAGAWA, J.; CAVARIANI, C. \& MACHADO, J.R. Adubação nitrogenada no perfilhamento da aveia-preta em duas condições de fertilidade do solo. Pesq. Agropec. Bras., 35:1071-1080, 2000.

NOGUEIRA, A.R.A. \& MOZETO, A.A. Interações químicas do sulfato e carbonato de cálcio em seis solos paulistas sob vegetação de cerrado. R. Bras. Ci. Solo, 14:1-6, 1990.

OLIVEIRA, E.L. \& PAVAN, M.A. Control of soil acidity in notillage system for soybean production. Soil Till. Res., 38:47$57,1996$.

PAVAN, M.A. \& OLIVEIRA, E.L. Corretivos da acidez do solo: experiências no Paraná. In: KAMINSKI, J., coord. Uso de corretivos da acidez do solo no plantio direto. Pelotas, Núcleo Regional Sul da Sociedade Brasileira de Ciência do Solo, 2000. p.61-76. (Boletim, 4)

QUAGGIO, J.A. Acidez e calagem em solos tropicais. Campinas, Instituto Agronômico, 2000. 111p.

QUAGGIO, J.A.; RAIJ, B.van; GALLO, P.B. \& MASCARENHAS, H.A.A. Resposta da soja à aplicação de calcário e gesso e lixiviação de íons no perfil do solo. Pesq. Agropec. Bras., 28:375-383, 1993. 
RAIJ, B. van; QUAGGIO, J.A.; CANTARELLA, H. \& ABREU, C.A. Interpretação de resultados de análise de solo. In: RAIJ, B.van; CANTARELLA, H.; QUAGGIO, J.A. \& FURLANI, A.M.C., eds. Recomendações de adubação e calagem para o Estado de São Paulo. Campinas, Instituto Agronômico, 1996. p.8-13.

RAIJ, B.van; ANDRADE, J.C.; CANTARELLA, H. \& QUAGGIO, J.A. Análise química para avaliação da fertilidade de solos tropicais. Campinas, Instituto Agronômico, 2001. 284p.

ROSSETTO, C.A.V. \& NAKAGAWA, J. Efeito da época de semeadura no desenvolvimento de plantas de aveia preta (Avena strigosa Schreb). Científica, 23:151-164, 1995.

SÁ, J.C.M. Manejo do solo no sistema de plantio direto. In: SIQUEIRA, J.O.; MOREIRA, F.M.S.; LOPES, A.S.; GUILHERME, L.R.G.; FAQUIN, V.; FURTINI NETO, A.E. \& CARVALHO, J.C., eds. Inter-relação fertilidade, biologia do solo e nutrição de plantas. Lavras, SBCS/UFLA/DCS, 1999. p.267-319.

SALERMO, A.R. \& VETTERLE, C.P. Avaliação de forrageiras de inverno no Baixo Vale do Itajaí, Santa Catarina. Florianópolis, EMPASC, 1984. 2p. (Comunicado Técnico, 76)
SEIXAS F.P.; MOREIRA, A.L.; GOMIDE C.A.M.; REIS, R.A. \& LUCA, S. Produção e germinação de sementes de cultivares de aveia sob irrigação em Jaboticabal-SP. Ci. Agrotecnol., 28:63-69, 2004.

STONE, L.F. \& SILVEIRA, P.M. Efeitos de sistemas de preparo na compactação do solo, disponibilidade hídrica e comportamento do feijoeiro. Pesq. Agropec. Bras., 34:8391, 1999.

SUMNER, M.E.; FARINA, P.M.W. \& HORST, V.J. Magnesium fixation: a possible cause of negative yield responses to lime applications. Comm. Soil Sci. Plant Anal., 9:955-1007, 1978.

TIRITAN, C.S. Alterações dos atributos químicos do solo e resposta do milho à calagem superficial e incorporada em região de inverno seco. Botucatu, Universidade Estadual Paulista, 2001. 108p. (Tese de Doutorado)

VITTI, G.C. Enxofre no solo. In: SIMPOSIO SOBRE INTERPRETAÇÃO DE ANÁLISE QUÍMICA DE SOLO E PLANTA PARA FINS DE ADUBAÇÃO, 1., Botucatu, 1988. Anais. Botucatu, FCA-UNESP/FEPAF/ANDA/ POTAFOS, 1988. 39p. 